\title{
Conservative treatment of juvenile with Chiari I malformation, syringomyelia, and scoliosis
}

\author{
Rhonda S Campo*, Elizabeth Janssen, Leah Tremonti \\ From 7th International Conference on Conservative Management of Spinal Deformities \\ Montreal, Canada. 20-22 May 2010
}

\section{Background}

Numerous studies suggest a non-chance association among Chiari, syringomyelia, and scoliosis, though the relationship remains a mystery. Studies suggest that more than sixty percent of patients receiving decompression surgery had no change (14\%) or a worsening (48\%) of their scoliosis symptoms. Curve reduction following Chiari treatment through the utilization of conservative scoliosis management only (i.e. bracing and physical therapy) has not been documented.

\section{Case presentation}

A seven year old female presenting with a 44 degree Cobb thoracolumbar curve (T5-L1) was subsequently diagnosed with Chiari I. MRIs showed patient had Chiari 1 malformation with approximately $10-11 \mathrm{~mm}$ of tonsillar ectopia. MRI scan of patient's spine showed that she had evidence of syringomyelia. The syrinx extended from approximately the C5 level through T11 level with two areas of focal dilation. Patient underwent a posterior fossa decompression and duraplasty. A C1 laminectomy was performed as well as a suboccipital decompression which extended laterally to the emissary veins. Part of the $\mathrm{C} 2$ lamina was removed. Intraoperative ultrasound revealed pistoning with a very minimal room present. Surgeon opened and coagulated the tonsil such that the bases of the tonsils were elevated to the level of the occiput. Six months following the decompression procedure, a standing AP view of the thoracolumbar spine revealed the angle between $\mathrm{T} 5$ and $\mathrm{L} 1$ measured 55 degrees. Eight months following the decompression surgery, patient began full-time treatment (dose defined as 23 hours per day) with a Rigo Systeme Cheneau asymmetric, partial-contact TLSO-type brace. Two years following the decompression surgery, patient was

Scoliosis Rehab, Columbus, Ohio, USA

Full list of author information is available at the end of the article trained in the Schroth-based method of exercises which she practices for 20 minutes daily, five times per week.

\section{Conclusion}

In the three years following the patient's Chiari surgery, she has been fitted for three Rigo Systeme Cheneau braces and has been exercising daily according to the personalized Schroth-based regime established for her. An in-brace XR Thoracic/Lumbar Spine Standing xray measurement of the thoracic curvature from the level of T5 through the level of L1 revealed a 19.9 degree curvature. Bracing and exercises should be tested in other patients following Chiari decompression to assess the possibility of improved curve reduction.

Published: 10 September 2010

doi:10.1186/1748-7161-5-S1-073

Cite this article as: Campo et al:: Conservative treatment of juvenile with Chiari I malformation, syringomyelia, and scoliosis. Scoliosis 2010 5(Suppl 1):073.

Submit your next manuscript to BioMed Central and take full advantage of:

- Convenient online submission

- Thorough peer review

- No space constraints or color figure charges

- Immediate publication on acceptance

- Inclusion in PubMed, CAS, Scopus and Google Scholar

- Research which is freely available for redistribution 